\title{
CORRESPONDENCE
}

\section{Platelets and ECMO: should we worry about count, function, or both? Response to Mazzeffi and Tanaka}

\author{
Darryl Abrams, ${ }^{*}$ Matthew R. Baldwin and Daniel Brodie
}

(C) 2016 Springer-Verlag Berlin Heidelberg and ESICM

Dear Editor,

We thank Drs. Mazzeffi and Tanaka for their thoughtful commentary [1] on our article [2]. The authors raise important points regarding the potential associations between and consequences of thrombocytopenia and bleeding. The intention of our study, however, was to investigate the association between ECMO and the development of thrombocytopenia, and we concluded that more studies are indeed needed to determine whether thrombocytopenia has a meaningful impact on the rates of hemorrhage in patients supported with ECMO.

Drs. Mazzeffi and Tanaka recently explored that relationship, demonstrating a correlation between the ECMO mortality and the rates of bleeding and transfusions [3]. However, taking this a step further may be problematic because any association between platelet counts and bleeding should not be construed as representing causality, as retrospective studies are not able to establish directionality. Furthermore, because ECMO may be associated with bleeding, and bleeding may be associated with thrombocytopenia, controlling for bleeding may identify an association between ECMO and platelets that does not, in fact, exist.

Drs. Mazzeffi and Tanaka's recent findings of increased odds of in-hospital mortality with increasing number of packed red blood cell transfusions are in line with previous data showing that red blood cell transfusions are associated with increased rates of morbidity and mortality in critically ill patients [4]. However, we have previously demonstrated in a comparable cohort of patients receiving venovenous ECMO that both bleeding and

\footnotetext{
*Correspondence: da2256@cumc.columbia.edu Division of Pulmonary and Critical Care, College of Physicians and Surgeons, Columbia University, New York, NY, USA
}

transfusion rates are very low when using a restrictive transfusion strategy in combination with a low anticoagulation target [5], such that this appears to be less of a factor in our population. The authors raise an excellent point about the potentially important role of platelet function. Because of the retrospective nature of our study, we did not assess platelet function, as this is not part of our routine ECMO management. However, we completely agree that this is an area that warrants further investigation.

\section{Compliance with ethical standards}

\section{Conflicts of interest}

None.

Accepted: 15 April 2016

Published online: 25 April 2016

\section{References}

1. Mazzeffi M, Tanaka K (2016) Platelets and ECMO: should we worry about count, function, or both? Intensive Care Med. doi:10.1007/ s00134-016-4360-1

2. Abrams D, Baldwin MR, Champion M, Agerstrand C, Eisenberger A, Bacchetta M, Brodie D (2016) Thrombocytopenia and extracorporeal membrane oxygenation in adults with acute respiratory failure: a cohort study. Intensive Care Med 42:844-852. doi:10.1007/s00134-016-4312-9

3. Mazzeffi M, Greenwood J, Tanaka K, Menaker J, Rector R, Herr D, Kon Z, Lee J, Griffith B, Rajagopal K, Pham S (2016) Bleeding, transfusion, and mortality on extracorporeal life support: ECLS Working Group on Thrombosis and Hemostasis. Ann Thorac Surg 101:682-689

4. Corwin HL, Gettinger A, Pearl RG, Fink MP, Levy MM, Abraham E, Maclntyre NR, Shabot MM, Duh MS, Shapiro MJ (2004) The CRIT Study: anemia and blood transfusion in the critically ill-current clinical practice in the United States. Crit Care Med 32:39-52

5. Agerstrand CL, Burkart KM, Abrams DC, Bacchetta MD, Brodie D (2015) Blood conservation in extracorporeal membrane oxygenation for acute respiratory distress syndrome. Ann Thorac Surg 99:590-595 